\title{
What happened to alcohol consumption and problems in the Nordic countries when alcohol taxes were decreased and borders opened?
}

\author{
Robin Room ${ }^{1,2,3}$, Kim Bloomfield ${ }^{4,5}$, Ulrike Grittner ${ }^{5}$, Nina-Katri Gustafsson ${ }^{1,6}$, Pia Mäkelä $^{7}$, Esa Österberg ${ }^{7}$, \\ Mats Ramstedt $^{1,8}$, Jürgen Rehm ${ }^{9,10,11}$, Matthias Wicki ${ }^{12}$, and Gerhard Gmel ${ }^{12}$ \\ ${ }^{1}$ Centre for Social Research on Alcohol and Drugs, Stockholm University, Stockholm, Sweden \\ ${ }^{2}$ School of Population Health, University of Melbourne, Melbourne, Australia \\ ${ }^{3}$ Centre for Alcohol Policy Research, Turning Point Alcohol and Drug Centre, Fitzroy, Australia \\ ${ }^{4}$ Centre for Alcohol and Drug Research, Aarhus University, Copenhagen, Denmark \\ ${ }^{5}$ Department for Biostatistics and Clinical Epidemiology, Charité - University Medicine Berlin, Berlin, Germany \\ ${ }^{6}$ Department of Sociology, Stockholm University, Stockholm, Sweden \\ ${ }^{7}$ National Institute for Health and Welfare, Helsinki, Finland \\ ${ }^{8}$ STAD Section, Centre for Dependency Disorders, Stockholm County Council, Stockholm, Sweden \\ ${ }^{9}$ Social \& Epidemiological Research Department, Centre for Addiction \& Mental Health, Toronto, Canada \\ ${ }^{10}$ Dalla Lana School of Public Health, University of Toronto, Toronto, Canada \\ ${ }^{11}$ Epidemiological Research Unit, Technische Universität Dresden, Dresden, Germany \\ ${ }^{12}$ Research Institute of Addiction Switzerland, Lausanne, Switzerland
}

\begin{abstract}
Aims: The study tests the effects of reductions in alcohol taxation and increases in travellers' allowances on alcohol consumption and related harm in Denmark, Finland, and southern Sweden. In late 2003 and early 2004, taxes on alcoholic beverages were reduced in Denmark and Finland, and the abolition of quantitative quotas on alcohol import for personal use from other European Union countries made cheaper alcohol more available in Denmark, Finland, and Sweden.

Method: Analyses of routine statistical register data and summaries of results from longitudinal and repeated cross-sectional population surveys and other previous analyses, with northern Sweden as a control site for secular trends.

Results: Contrary to expectations, alcohol consumption-as based on register data-increased only in Finland and not in Denmark and southern Sweden, and self-reported survey data did not show an increase in any site. In Finland, alcoholattributable harms in register data increased, especially in people with low socio-economic status. Few such effects were found in Denmark and southern Sweden. Neither did results for self-reported alcohol-attributable problems show any general increases in the three sites. These results remained after controlling for regression to the mean and modelling of drop-outs.
\end{abstract}

Conclusions: Harms measured in register data did tend to increase in the short term with the policy change, particularly in Finland, where the tax changes were broader. But reducing price and increasing availability does not always increase alcohol consumption and harm. Effects are dampened in affluent societies, and other factors may intervene. The results for Finland also suggest some limits for general population surveys in testing for relatively small policy effects.

Increasing the prices of alcoholic beverages by taxation or otherwise is considered one of the most effective and costeffective means of controlling a population's alcohol consumption (Anderson, Chisholm, \& Fuhr, 2009; Babor et al., 2010) backed by substantial evidence (Babor et al.,
2010; Fogarty, 2006; Gallet, 2007; Wagenaar, Salois, \& Komro, 2009). Theoretically it is based on laws of supply and demand that date from Adam Smith (1977). If their prices increase, alcoholic beverages will be consumed less, and vice-versa-even though demand for them is

Correspondence: Robin Room, Turning Point Alcohol \& Drug Centre, 54-62 Gertrude St., Fitzroy, Vic. 3065, Australia. Fax: +61 394163420 , Tel.: +61 3 8413 8430, E-mail: robinr@turningpoint.org.au

Declaration of interests: The study has received support from the Joint Committee for Nordic Research Councils for the Humanities and the Social Sciences (NOSHS, project 20071), the US National Institute on Alcohol Abuse and Alcoholism (R01 AA014879) and national funds. For Sweden, partial funding for the 2003 data collection came from Systembolaget. For Denmark, data collection was supported by the Danish Medical Research Council (contract no. 22-02-374), as well as the Danish Health Insurance Fund (journal numbers 2003B105, 2004B195, 2005B093). There were no constraints by funders on publishing. None of the researchers is connected with the tobacco, alcohol, pharmaceutical or gaming industries or bodies substantially funded by these.

Keywords: alcohol, taxation, price, availability, alcohol consumption, alcohol-attributable harm, mortality, cross-border trade, Nordic countries 
somewhat inelastic (in meta-analyses a $1 \%$ increase in price produces an average $0.5 \%$ decrease in consumption) (Gallet, 2007; Wagenaar et al., 2009). A population's level of alcohol consumption in turn strongly influences levels of alcohol-related harm (Babor et al., 2010).

Lower prices can increase demand by attracting customers not only locally but also from a distance. For the latter group, the effective price includes the effort and costs required to travel to make the purchase, in addition to the product price. Economists have used a gravity model of distance effects, whereby the attraction of sellers to a distant commodity is inverse to the square of the distance (Buch, Kleinert, \& Toubal, 2004). A study of the effect of a 1995 increase in the amount of alcohol Swedish travellers could bring from Denmark without further taxes found a pattern of decline in sales in Sweden conforming to this gravity model (Norström, 2000).

Policy changes in Denmark, Finland, and Sweden over a seven-month period in 2003-2004 offered a natural opportunity to test the effects of changes in alcohol price and availability in these countries (Table 1) (Mäkelä, Bloomfield, Gustafsson, Huhtanen, \& Room, 2008). There were substantial changes in travellers' allowances for bringing alcohol home from other European Union countries without further tax. In fact, imports for the traveller's own use became unlimited, and border checks on such imports by customs authorities were disallowed unless illicit trading was suspected. The Danish and Finnish governments responded in advance by lowering taxes, to counter the attraction of lower prices in neighbouring countries (Karlsson \& Österberg, 2009a). The Danish spirits tax reduction of $45 \%$ resulted in a $23.2 \%$ drop in the retail price of spirits (Skatteministeriet, 2010). Finnish alcohol taxes were lowered by an average of 33\%, resulting in cuts in off-premise prices ranging from $3 \%$ for wine to $36 \%$ for cheaper spirits (Mäkelä \& Österberg, 2009).

The study aimed to test the hypotheses that both a drop in alcohol taxes and the effective end of limits on travellers' alcohol imports would contribute to rises in alcohol consumption levels and in rates of alcohol-related problems, both where the tax had been lowered (Finland and Denmark) and in places proximate to lower-tax areas (southern Sweden, and also Finland and Denmark as proximate to Estonia and Germany, respectively), in comparison to a little-affected control site (northern Sweden). It was hypothesised that the rises in consumption and problems would be immediate (in the first year), and would continue in the medium term (2-3 years afterward). The original intention to test in Sweden the separate effects of the Danish tax change and the abolition of limits on travellers' imports was abandoned when it became clear that no short-term difference in effect was apparent.

Earlier papers have tested these hypotheses using repeated cross-sectional and longitudinal population survey samples. This paper adds analyses of trends in register data on alcohol consumption and harms, and summarises the survey-based analyses in interpreting the results seen through the window-frames of register and survey data.

\section{Table 1}

Nordic alcohol policy changes studied: Travellers' allowances and anticipatory tax changes

\begin{tabular}{|c|c|c|c|c|c|}
\hline & $\begin{array}{l}\text { Travellers' allowances prior to } \\
\text { change, from named countries }\end{array}$ & $\begin{array}{l}\text { Indicative amount } \\
\text { assumed for personal } \\
\text { use after change }\end{array}$ & $\begin{array}{c}\text { Date of change in } \\
\text { travellers' } \\
\text { allowances }\end{array}$ & $\begin{array}{c}\text { Domestic tax change, in } \\
\%\end{array}$ & $\begin{array}{c}\text { Date of tax } \\
\text { change }\end{array}$ \\
\hline \multirow[t]{5}{*}{ Denmark } & From Germany (\& EU): & & 1 Jan., 2004 & & 1 Oct., 2003 \\
\hline & 1.51 spirits & 10 l spirits & & spirits taxes $-45 \%$ & \\
\hline & 201 fortified wine & 201 fortified wine & & & \\
\hline & 901 table wine & 901 table wine & & & \\
\hline & 110 l beer & $110 \mathrm{l}$ beer & & & \\
\hline \multirow[t]{5}{*}{ Finland } & From Estonia: & & 1 May, 2004 & & 1 March, 2004 \\
\hline & 11 spirits & 101 spirits & & spirits taxes $-44 \%$ & \\
\hline & & 201 fortified wine & & fortified wine taxes $-40 \%$ & \\
\hline & 2 l wine & 901 table wine & & $\begin{array}{l}\text { table wine taxes } \\
-10 \%\end{array}$ & \\
\hline & 151 beer & $110 \mathrm{l}$ beer & & beer taxes $-32 \%$ & \\
\hline \multirow[t]{5}{*}{ Sweden } & From Denmark, Germany (\& EU): & & 1 Jan, 2004 & -- & -- \\
\hline & 51 spirits & $10 \mathrm{l}$ spirits & & & \\
\hline & 61 fortified wine & 201 fortified wine & & & \\
\hline & $52 \mathrm{l}$ table wine & 901 table wine & & & \\
\hline & 641 beer & 1101 beer & & & \\
\hline
\end{tabular}


Method

\section{Design}

For purposes of the study, "southern Sweden" was defined as those regions close to the bridge or ferries to Denmark (the city of Gothenburg and the counties to the Southeast of it) and "northern Sweden" as those counties north and west of but outside the Stockholm metropolitan area, excluding municipalities in the far north within $150 \mathrm{~km}$ of the Finnish border (Mäkelä et al., 2008). “Northern Sweden” was taken as a control site under the presumption that it would be little affected by either policy change, given its considerable distances from places with lower prices.

General population surveys, both longitudinal and repeated cross-sectional, and routinely collected register data were used to test the hypotheses. Population surveys covering at least persons aged 16-69 (15-year-olds were included in Finland, and up to age 80 in Sweden) were conducted in each of the four sites in the third quarter of 2003, before any policy changes, with further fourth quarter samples in Sweden in 2003 and 2004. These samples were reinterviewed, and a new cross-sectional sample collected, annually in each of 2004, 2005, and 2006. The smallest number interviewed among the new samples in each site for each of the four years was 972. Response/cooperation rates ranged between 33\% and 60\% (Bloomfield, Wicki, Gustafsson, Mäkelä, \& Room, 2010). In the longitudinal samples, by the fourth interview in 2006, the numbers of respondents were 971 for Denmark, 875 for Finland, 1,501 for southern and 1,433 for northern Sweden (Mäkelä, Bloomfield, Gustafsson, \& Room, 2007).

Results from these survey series are reported in detail elsewhere (e.g., Bloomfield et al., 2010; Mäkelä et al., 2007; Mäkelä et al., 2008). These results are drawn on here in comparison with results from other sources. The statistical analysis newly reported in this paper is primarily of register data routinely cumulated by public agencies for the four study sites, including recorded and estimated unrecorded alcohol consumption data, alcohol-related hospitalisation, and mortality data (primary cause except as noted), and police statistics for assaults, drink-driving arrests, and police handling of drunkenness. Mortality, morbidity, and police statistical data were derived from the National Board of Health (Sundhedsstyrelsen) in Denmark, from Statistics Finland and the National Institute for Health and Welfare in Finland, and from the National Board of Health and Welfare (Socialstyrelsen) and the National Council for Crime Prevention (BRA) in Sweden. Sources for consumption data are listed in Table 2. Estimates of unrecorded consumption are based on survey studies mostly on yearly bases. In Finland and Sweden figures for travellers' alcohol imports, the most important indicator of unrecorded alcohol consumption, are based on a continuing survey series where respondents are interviewed either on a weekly or monthly basis. The period surveyed is two weeks in Finland and one month in Sweden. In Denmark the two main sources of data for unrecorded alcohol consumption are both provided by the analysis institute
GfK Group. The Danish tax ministry commissions GfK Group to conduct a survey of Danish travellers' imports. In addition the GfK Group also uses data from a web-based panel called "ConsumerScan". These two surveys are the two main sources of data for unrecorded alcohol consumption in Denmark (Skatteministeriet, 2010)

\section{Statistical analysis}

In analysing the surveys, changes in levels and patterns of consumption and rates of alcohol-attributable problems were compared across years and with the control site, using multivariate statistics. Separate sub-studies analyzed the effects of regression to the mean (Gmel, Wicki, Rehm, \& Heeb, 2008; Ripatti \& Mäkelä, 2008) and dropout (Grittner, Gmel, Ripatti, Bloomfield, \& Wicki, 2011; Ripatti \& Mäkelä, 2007). The statistical analyses of the survey data have been reported in papers such as those referenced above. The present paper newly adds analysis of registry data. In the register data rates of harm were agestandardized to the average Nordic population (Kahn \& Sempos, 1989). As an indication of the strength of a finding of difference, short-term effects of the policy changes on consumption and alcohol-related health and police indicators were tested by comparing changes from 2003-2004 with changes between pairs of other years 20002007, two or three prior and three following years, i.e., changes between 2000-2001, 2001-2002, etc. (one-sample $t$-test with the difference between 2003 and 2004 being the reference). The time series of 2000-2007 was too short to apply full time-series analysis such as ARIMA-modelling. The rationale to test the 2003-2004 difference against the differences between other successive years was as follows. A test of pre- against post-intervention years would spuriously find an effect if there was an underlying general increasing or decreasing trend in the data. In this case post measures would generally be higher (lower) compared with pre-intervention measures, due to this common underlying trend. Differencing between two subsequent years filters out these common trends and focuses on relative changes between years. If there is a lasting shift (step) then this would be reflected in the change between 2003 and 2004, while all changes between other years would be small. If there is a short-term "pulse" again this would be reflected in the change between 2003 and 2004. Unfortunately the analysis cannot differentiate between long-term and shortterm effects. We therefore interpret significant findings cautiously as short-term changes.

\section{Results}

\section{Register data}

Denmark and southern Sweden did not show an increase in alcohol consumption over the years. In fact estimated total consumption showed a slightly decreasing trend after 2003, except for a small rise in southern Sweden in 2004 (see Table 2). In Denmark there was some evidence of consumers switching from beer and wine to spirits as the relative price of spirits fell; this effect tended to dissipate after two years (Bloomfield et al., 2010). Only a minority 
Table 2

Alcohol consumption, recorded and estimated total, in litres per capita for 2003, and indexed to 2003 for other years

\begin{tabular}{|c|c|c|c|c|c|c|c|c|c|}
\hline & \multirow{2}{*}{$\begin{array}{c}\begin{array}{c}\text { Litres per } \\
\text { capita }\end{array} \\
2003 \\
\end{array}$} & \multicolumn{8}{|c|}{ Indexed consumption per capita $(2003=100 \%)$} \\
\hline & & 2000 & 2001 & 2002 & 2003 & 2004 & 2005 & 2006 & 2007 \\
\hline \multicolumn{10}{|c|}{ Estimated total consumption (incl. unrecorded) } \\
\hline Denmark & 10.77 & 101.0 & 98.9 & 98.6 & 100.0 & 94.6 & 96.1 & 90.6 & 92.0 \\
\hline Finland & 9.37 & 94.3 & 95.4 & 99.3 & 100.0 & 109.6 & 112.4 & 110.0 & 112.0 \\
\hline Sweden-southern & 9.10 & & 86.8 & 97.1 & 100.0 & 103.0 & 97.6 & 90.4 & 91.5 \\
\hline Sweden-northern & 7.01 & & 85.2 & 96.1 & 100.0 & 106.4 & 102.1 & 107.3 & 100.4 \\
\hline \multicolumn{10}{|c|}{ Recorded total consumption } \\
\hline Denmark & 10.60 & 101.9 & 100.9 & 99.1 & 100.0 & 97.2 & 98.1 & 94.3 & 94.3 \\
\hline Finland & 7.67 & 91.8 & 95.7 & 99.1 & 100.0 & 106.5 & 107.3 & 109.6 & 113.3 \\
\hline Sweden-southern & 4.89 & & 92.8 & 101.2 & 100.0 & 94.6 & 94.0 & 98.5 & 101.0 \\
\hline \multirow[t]{3}{*}{ Sweden-northern } & 5.79 & & 87.2 & 96.1 & 100.0 & 97.4 & 98.4 & 103.6 & 107.8 \\
\hline & Litres per capita & \multicolumn{5}{|c|}{ Short-term effect 2003-2004 } & & & \\
\hline & 2003 & $t$-test & & & Direction o & & & & \\
\hline \multicolumn{10}{|c|}{$\begin{array}{l}\text { Estimated total consumption (incl. unrecorded) } \\
\text { (i) }\end{array}$} \\
\hline Denmark & 10.77 & 4.295 & & & ע & & & & \\
\hline Finland & 9.37 & -9.512 & $<0$. & & $\pi$ & & & & \\
\hline Sweden-southern & 9.10 & -0.842 & & & & & & & \\
\hline Sweden-northern & 7.01 & -1.406 & & & & & & & \\
\hline \multicolumn{10}{|c|}{ Recorded total consumption } \\
\hline Denmark & 10.60 & 2.735 & & & ע & & & & \\
\hline Finland & 7.67 & -7.106 & $<0$. & & $\pi$ & & & & \\
\hline Sweden-southern & 4.89 & 4.576 & & & ע & & & & \\
\hline Sweden-northern & 5.79 & 5.713 & & & ע & & & & \\
\hline
\end{tabular}

Note. Arrows show significant short-term effects for 2003 to 2004 relative to general trend (one-sample t-test, $\mathrm{p}<.05$ ): $\boldsymbol{\lambda}=$ stronger increase or weaker decrease; $\boldsymbol{\nabla}$ = stronger decrease or weaker increase. Significance levels: $n s$ non-significant, ${ }^{*} p<0.05$, ${ }^{* *} p<0.01$, ${ }^{* * *} p<0.001$. Sources: Denmark: (Karlsson \& Österberg, 2009); Finland: (Yearbook of Alcohol and Drug Statistics, 2009); Sweden: (Ramstedt, Axelsson, Engdahl, \& Svensson, 2009).

of Danish survey respondents reported increased imports from Germany after removal of the travellers' import limits; the longer-term trend after the change was a decrease in reported importing, although the rise persisted among a smaller group of "dedicated" private importers (Grittner \& Bloomfield, 2009; Skatteministeriet, 2010). In Finland, recorded per capita consumption increased over all years, but the increase was steeper in 2004, after the tax changes, compared to 2000-2003 and 2004-2007 (onesample $t$-test, $p=0.001$, Table 2) (Mäkelä \& Österberg, 2009).

For police statistics, in Finland the results were mixed, with a short-term rise in drink-driving arrests and drunks taken into custody, but little short-term change in assault rates (Table 3). There was no substantial change in police figures in Denmark or southern Sweden between 2003 and 2004, though in Denmark there was a rise in drink-driving arrests after 2004, probably partly reflecting increased enforcement (Justitsministeren, 2005), and in southern Sweden a rise in assaults after 2004 and in drink-driving arrests after 2005.

For alcohol-relevant mortality (Table 4), in Finland three of the four categories showed a jump in rates between 2003 and 2004, with a further increase in liver disease mortality in following years, reflected also in the alcohol-specific mortality. There was no clear trend in liver disease or in overall alcohol-specific mortality in either Denmark or southern Sweden; alcohol use disorder deaths showed a short-term pulse in 2004 in both locations. Alcohol poisoning deaths are too uncommon in both places for meaningful trend analysis.

There was a jump from 2003 to 2004 in alcohol-relevant hospitalizations for all three indicators in Finland (Table 5), with a continued increase afterwards for alcoholic liver disease. Danish hospitalizations for liver disease declined 
Table 3

Alcohol-relevant police statistics, per 10,000 population in 2003, and indexed to 2003 for other years

\begin{tabular}{|c|c|c|c|c|c|c|c|c|c|}
\hline & \multirow{2}{*}{$\begin{array}{c}\text { Rate per 10,000 } \\
2003\end{array}$} & \multicolumn{8}{|c|}{ Indexed rates per $10,000(2003=100 \%)$} \\
\hline & & 2000 & 2001 & 2002 & 2003 & 2004 & 2005 & 2006 & 2007 \\
\hline \multicolumn{10}{|l|}{ Assaults } \\
\hline Denmark & 19.91 & 86.4 & 89.6 & 94.3 & 100.0 & 103.0 & 105.5 & 106.9 & 105.7 \\
\hline Finland & 55.29 & 97.1 & 95.5 & 97.3 & 100.0 & 102.9 & 104.9 & 105.9 & 118.2 \\
\hline Sweden-southern & 66.66 & 93.6 & 97.4 & 99.3 & 100.0 & 102.9 & 113.2 & 118.3 & 123.5 \\
\hline Sweden-northern & 63.50 & 86.0 & 87.6 & 91.9 & 100.0 & 104.2 & 112.8 & 120.4 & 129.2 \\
\hline \multicolumn{10}{|l|}{ Drink driving arrests } \\
\hline Denmark & 18.31 & 94.6 & 96.1 & 97.6 & 100.0 & 102.4 & 108.8 & 111.9 & 114.5 \\
\hline Finland & 43.79 & 100.4 & 99.9 & 100.7 & 100.0 & 108.4 & 103.4 & 99.2 & 104.0 \\
\hline Sweden-southern & 16.00 & 125.8 & 101.3 & 102.8 & 100.0 & 104.4 & 105.3 & 112.8 & 115.2 \\
\hline Sweden-northern & 17.71 & 115.5 & 94.9 & 97.4 & 100.0 & 104.3 & 106.2 & 112.6 & 118.5 \\
\hline \multicolumn{10}{|c|}{ Arrests/handling for drunkenness } \\
\hline Finland & 182.53 & 102.5 & 101.1 & 101.0 & 100.0 & 110.7 & 106.2 & 103.4 & 101.0 \\
\hline
\end{tabular}

\begin{tabular}{|c|c|c|c|c|}
\hline & \multirow{2}{*}{$\begin{array}{c}\text { Rate per } 10,000 \\
2003\end{array}$} & \multicolumn{3}{|c|}{ Short-term effect 2003-2004 } \\
\hline & & $t$-test & $p$-value & Direction of effect \\
\hline \multicolumn{5}{|l|}{ Assaults } \\
\hline Denmark & 19.91 & -0.302 & $0.775^{n s}$ & \\
\hline Finland & 55.29 & 0.035 & $0.973^{n s}$ & \\
\hline Sweden-southern & 66.66 & 1.195 & $0.285^{n s}$ & \\
\hline Sweden-northern & 63.50 & 1.897 & $0.116^{n s}$ & \\
\hline \multicolumn{5}{|l|}{ Drink driving arrests } \\
\hline Denmark & 18.31 & 0.942 & $0.416^{n s}$ & \\
\hline Finland & 43.79 & -6.343 & $0.001^{* *}$ & $\pi$ \\
\hline Sweden-southern & 16.00 & -1.507 & $0.192^{n s}$ & \\
\hline Sweden-northern & 17.71 & -1.105 & $0.320^{n s}$ & \\
\hline \multicolumn{5}{|c|}{ Arrests/handling for drunkenness } \\
\hline Finland & 182.53 & -20.158 & $<0.001^{* * *}$ & $\mathbf{y}$ \\
\hline
\end{tabular}

Note. Police statistics on handling of drunkenness available only for Finland. Significance levels: $n s$ non-significant, ${ }^{*} p<0.05$, ${ }^{* *} p<0.01$, $* * * p<0.001$.

Arrows show significant short-term effects for 2003 to 2004 relative to general trend. (one-sample $t$-test, $p<0.05$ ): $\boldsymbol{\lambda}=$ stronger increase or weaker decrease; $\boldsymbol{y}=$ stronger decrease or weaker increase

and for alcohol use disorders increased in 2004, but the changes were not sustained, and the overall alcohol-specific morbidity showed little change. Southern Sweden showed a sustained rise in liver disease (which was matched in northern Sweden), but no substantial change in the other indicators.

More in-depth time series analyses largely support the pattern of findings. In Finland, the price cuts were estimated to have resulted in no increase in assaults (Sirén \& Lehti, 2006) but a significant increase in alcohol-related mortality (Herttua, Mäkelä, \& Martikainen, 2008) and hospitalizations (Herttua, 2010) that was largest for peoplein the age group 50-69 years and for liver disease mortality. In age groups below 40 years, only alcohol- related hospitalizations of men increased. All-cause mortality was shown to have decreased (Herttua, 2010), but this was not specific to causes for which a protective effect of alcohol has been proposed. In the working-age population, the rise in alcohol-related mortality in years 2004 and 2005 was strongest among non-employed people (Herttua et al., 2008).

Time series analyses for Denmark and southern Sweden of monthly assaults and for southern Sweden of drink-driving arrests found no significant effects of the 2003 spirits tax cut or the change in traveller's allowances (Bloomfield, Rossow, \& Norström, 2009; Gustafsson, 2010a). In Denmark, time-series analyses by month found a significant effect of the spirits tax decrease in increasing 
hospitalizations for intoxication among those aged 15 or younger (who cannot legally buy alcohol), but not for older persons (Bloomfield et al., 2009). Alcohol poisoning hospitalizations increased somewhat in southern Sweden after the removal of import restrictions, particularly among those aged 50 or more (Gustafsson, 2010a).

\section{Self-report data}

Overall, the main hypotheses regarding relative increases of average level of alcohol consumption as a consequence of lower prices and/or increased availability were clearly not supported by the self-report data. Neither the longitudinal study nor the repeated cross-sectional studies based on surveys showed any increase in average volume of consumption or in binge drinking for any country, or for any major subgroups within countries, in short or medium term, whether or not a comparison to northern Sweden was made (Grittner, Gustafsson, \& Bloomfield, 2009; Gustafsson, 2010a, 2010b; Mustonen, Mäkelä, \& Huhtanen, 2007). This basic conclusion was still the same after controlling for effects of regression to the mean (Ripatti \& Mäkelä, 2008) and modelling the effects of dropouts (Grittner et al., 2011; Ripatti \& Mäkelä, 2007). Also, omissions from the survey sampling frame cannot account for the difference from register results (Mäkelä \& Huhtanen, 2010). Analyses of a separate survey series in Finland, however, did find an increase in consumption from 2000-2003 to 2004-2008, particularly in those aged 45 and over and with less education (Helakorpi, Mäkelä, \& Uutela, 2010), and also found a steep increase between 2003 and 2004 (Helakorpi, Patja, Prättälä, \& Uutela, 2005). Additionally, survey data on travellers' imports does reveal a rise in imports in southern Sweden in early 2004, but there was a corresponding fall in sales in the stores in southern Sweden, and the rise was mostly limited to one quarter (Ramstedt \& Gustafsson, 2009).

An analysis of self-reported problems due to drinking produced results similar to those on self-reported consumption: no significant increases, compared to trends in northern Sweden, were reported in either the short or the medium term, for either dependence symptoms or extrinsic problems from drinking (Bloomfield et al., 2010; Gustafsson, 2010a).

\section{Discussion}

\section{Testing the study's hypotheses}

If the results of Tables 3-5 for Denmark, Finland and Southern Sweden are looked at overall (excluding the first indicator in Tables 4 and 5, which includes cases also counted below), there were 11 significant short-term effects in the hypothesised direction (six of them from Finland), compared with two in the opposite direction, with nine tests showing no significant short-term effect. This set of findings could be interpreted as modest evidence in support of the hypotheses on the effects of the policy changes on alcohol-related harms as they are measured in case registers of social and health agencies.
On the other hand, except for the register series for Finland, the results of the study did not generally support the hypotheses with which it started. In Denmark, neither the alcohol sales statistics nor the survey data found an increase in total alcohol consumption, and there were conflicting results from the mortality and morbidity series. The picture was much the same for the effects in southern Sweden. Neither the survey data nor the register data found the expected effect of increased availability and lower prices across the bridge or a short ferry ride away. The only substantial rises in health consequences in southern Sweden (for alcohol use disorder mortality and for liver disease hospitalisations) were matched in northern Sweden.

For Finland, there is more evidence of change. The alcohol sales statistics show a jump between 2003 and 2004. This is not matched in the present study's survey data on amounts of consumption, although as noted another survey series did find a rise. Estimated home stocks of alcohol did not change from 2003 to 2004 (Mustonen, Mäkelä, Huhtanen, Metso, \& Raitasalo, 2005), so this does not explain the discrepancy. A majority of the register-data indicators do show a substantial rise in alcohol harm rates in 2004, mostly persisting in the following years; for some indicators, the rise is substantially greater than the increase in alcohol consumption. The findings suggest that in the short term marginalised heavy drinkers were particularly affected by the increase in availability.

The trends in northern Sweden were generally upward. This meant that comparisons of trends in Denmark or southern Sweden with the control site were even farther from matching the original hypotheses of the study than the site-specific trends in statistics.

\section{Potential influences on the findings}

General economic and alcohol consumption trends. Other factors besides the changes studied affect alcohol consumption levels (Room, Österberg, Ramstedt, \& Rehm, 2009). But there were no other large changes in alcohol availability in Denmark or Sweden around 2003-2004, and few obvious changes in other factors potentially influencing consumption. The economy in both countries was prosperous at the time. However, there was a substantial rise in petrol prices in 2004, which seems to have depressed cross-border alcohol purchasing (Lhachimi, 2006). The economy was also growing in Finland in the early 2000s, the effect of which was a small growth in alcohol consumption in the years preceding the 2004 tax cuts. In other words, even without the tax cuts, an increase in consumption, although clearly a smaller increase, would have been expected.

The general trends in alcohol consumption in each of the study sites in the years before 2003-2004 should also be considered in interpreting the study's findings. Northern Sweden has traditionally had a lower consumption rate than the rest of Sweden, but in the 1990s and early 2000s had been gradually approaching the national average (Gustafsson, 2010a). In light of this history, the increases 
Table 4

Standardized alcohol-relevant mortality, per 10,000 population in 2003, and indexed to 2003 for other years

\begin{tabular}{|c|c|c|c|c|c|c|c|c|c|}
\hline & \multirow{2}{*}{$\begin{array}{c}\begin{array}{c}\text { Standardized } \\
\text { rate per 10,000 }\end{array} \\
2003\end{array}$} & \multicolumn{8}{|c|}{ Indexed standardized rates per $10,000(2003=100 \%)$} \\
\hline & & 2000 & 2001 & 2002 & 2003 & 2004 & 2005 & 2006 & 2007 \\
\hline \multicolumn{10}{|c|}{ Alcohol-specific mortality $^{1}$} \\
\hline Denmark & 1.92 & 127.6 & 133.3 & 105.7 & 100.0 & 104.2 & 100.0 & 106.8 & \\
\hline Finland & 2.95 & 97.3 & 97.3 & 94.6 & 100.0 & 118.0 & 126.4 & 125.4 & 133.6 \\
\hline Sweden-southern & 2.39 & 100.8 & 101.3 & 90.0 & 100.0 & 98.7 & 102.9 & 92.9 & 102.5 \\
\hline Sweden-northern & 2.07 & 92.3 & 94.7 & 107.2 & 100.0 & 102.4 & 103.9 & 106.8 & 107.2 \\
\hline \multicolumn{10}{|l|}{ Alcohol poisoning $^{2}$} \\
\hline Denmark & $0.01^{3}$ & & & & & & & & \\
\hline Finland & 0.97 & 107.2 & 100.0 & 90.7 & 100.0 & 116.5 & 104.1 & 109.3 & 108.2 \\
\hline Sweden-southern & 0.06 & 50.0 & 133.3 & 83.3 & 100.0 & 116.7 & 166.7 & 116.7 & 183.3 \\
\hline Sweden-northern & 0.18 & 55.6 & 122.2 & 105.6 & 100.0 & 72.2 & 66.7 & 100.0 & 88.9 \\
\hline \multicolumn{10}{|c|}{ Alcohol use disorders (F10) } \\
\hline Denmark & 0.56 & 166.1 & 175.0 & 116.1 & 100.0 & 119.6 & 112.5 & 114.3 & \\
\hline Finland & 0.28 & 117.9 & 110.7 & 82.1 & 100.0 & 96.4 & 114.3 & 117.9 & 96.4 \\
\hline Sweden-southern & 0.51 & 131.4 & 84.3 & 94.1 & 100.0 & 123.5 & 92.2 & 76.5 & 78.4 \\
\hline Sweden-northern & 0.47 & 102.1 & 83.0 & 93.6 & 100.0 & 123.4 & 91.5 & 102.1 & 89.4 \\
\hline \multicolumn{10}{|c|}{ Alcoholic liver disease (K70) } \\
\hline Denmark & 1.23 & 104.1 & 108.9 & 101.6 & 100.0 & 95.9 & 93.5 & 103.3 & \\
\hline Finland & 1.22 & 86.1 & 95.9 & 104.9 & 100.0 & 128.7 & 148.4 & 146.7 & 171.3 \\
\hline Sweden-southern & 0.37 & 78.4 & 86.5 & 70.3 & 100.0 & 83.8 & 108.1 & 100.0 & 105.4 \\
\hline \multirow[t]{3}{*}{ Sweden-northern } & 0.30 & 80.0 & 76.7 & 110.0 & 100.0 & 120.0 & 143.3 & 130.0 & 136.7 \\
\hline & $\begin{array}{c}\text { Standardized rate } \\
\text { per } 10,000\end{array}$ & \multicolumn{5}{|c|}{ Short-term effect 2003-2004 } & & & \\
\hline & 2003 & $t$-test & $p$-value & & tion of $e$ & & & & \\
\hline \multicolumn{10}{|c|}{ Alcohol-specific mortality $^{1}$} \\
\hline Denmark & 1.92 & -1.481 & $0.213^{n s}$ & & & & & & \\
\hline Finland & 2.95 & -7.459 & $<0.001^{* * *}$ & & $\pi$ & & & & \\
\hline Sweden-southern & 2.39 & 0.456 & $0.667^{n s}$ & & & & & & \\
\hline Sweden-northern & 2.07 & -0.125 & $0.906^{n s}$ & & & & & & \\
\hline \multicolumn{10}{|l|}{ Alcohol poisoning $^{2}$} \\
\hline Denmark & $0.01^{3}$ & & & & & & & & \\
\hline Finland & 0.97 & -5.467 & $0.003^{* *}$ & & $\pi$ & & & & \\
\hline Sweden-southern & 0.06 & 0.117 & $0.911^{\text {ns }}$ & & & & & & \\
\hline Sweden-northern & 0.18 & 2.831 & $0.037^{*}$ & & $y$ & & & & \\
\hline \multicolumn{10}{|c|}{ Alcohol use disorders (F10) } \\
\hline Denmark & 0.56 & -2.845 & $0.047^{*}$ & & $\pi$ & & & & \\
\hline Finland & 0.28 & 0.074 & $0.944^{\text {ns }}$ & & & & & & \\
\hline Sweden-southern & 0.51 & -3.893 & $0.011^{*}$ & & $\pi$ & & & & \\
\hline Sweden-northern & 0.47 & -4.034 & $0.010^{* *}$ & & $\pi$ & & & & \\
\hline \multicolumn{10}{|c|}{ Alcoholic liver disease (K70) } \\
\hline Denmark & 1.23 & 1.576 & $0.190^{n s}$ & & & & & & \\
\hline Finland & 1.22 & -4.096 & $0.009^{* *}$ & & $\pi$ & & & & \\
\hline Sweden-southern & 0.37 & 3.220 & $0.023^{*}$ & & ע & & & & \\
\hline Sweden-northern & 0.30 & -1.811 & $0.130^{\text {ns }}$ & & & & & & \\
\hline \multicolumn{10}{|c|}{$\begin{array}{l}\text { Note. Significance levels: } n s \text { non-signifiant, }{ }^{*} p<0.05,{ }^{* *} p<0.01, * * * p<0.001 \text {. Arrows show significant short-term effects for } 2003 \text { to } 2004 \\
\text { relative to general trend (one-sample } t \text {-test, } p<0.05 \text { ): } \boldsymbol{\lambda}=\text { stronger increase or weaker decrease; } \boldsymbol{\Psi}=\text { stronger decrease or weaker increase. All } \\
\text { rates have been standardised (direct standardization), with average distribution of age groups in DK, FI, southern SE and northern SE } 2000-2007 \\
\text { used as the standard population. }{ }^{1} \text { Based on these ICD-10 codes: DK =F10, G31.2, G62.1, I42.6, K29.2, K70, K86.0, X45, X65, Y15; FI =F10, } \\
F 19 \text { (with alcohol), G31.2, G40.51, G62.1, G72.1, I42.6, K29.2, K70, K85.2, K86.0, Q86.0, X45; SE = E24.4, F10, G31.2, G62.1, I42.6, K29.2, } \\
\text { K70, K85.2, K86.0, O35.4, P04.3 Q86, T51,Y90.1-Y90.9, Y91.1-Y91.9, Z50.2, Z71.4, Z72.1. This category includes contributory causes in } \\
\text { Sweden. }{ }^{2} \text { Based on these ICD codes: DK = X45, X65, Y15; FI = X45; SE = X45. }\end{array}$} \\
\hline
\end{tabular}


Table 5

Alcohol-relevant hospitalization, per 10,000 population in 2003 (primary cause, standardized rates), and indexed to 2003 for other years

\begin{tabular}{|c|c|c|c|c|c|c|c|c|c|}
\hline & \multirow{2}{*}{$\begin{array}{c}\begin{array}{c}\text { Standardized } \\
\text { rate per } 10,000\end{array} \\
2003\end{array}$} & \multicolumn{8}{|c|}{ Indexed standardized rates per $10,000(2003=100 \%)$} \\
\hline & & 2000 & 2001 & 2002 & 2003 & 2004 & 2005 & 2006 & 2007 \\
\hline \multicolumn{10}{|c|}{ Alcohol-specific mortality $^{1}$} \\
\hline Denmark & 44.95 & 98.5 & 101.2 & 97.9 & 100.0 & 102.1 & 97.7 & 101.5 & 99.4 \\
\hline Finland & 46.09 & 108.2 & 102.5 & 102.0 & 100.0 & 108.6 & 108.1 & 105.3 & 107.4 \\
\hline Sweden-southern & 16.06 & 104.7 & 96.9 & 99.8 & 100.0 & 100.7 & 104.7 & 106.1 & 103.1 \\
\hline Sweden-northern & 15.83 & 111.9 & 117.5 & 112.3 & 100.0 & 104.6 & 104.2 & 107.4 & 115.5 \\
\hline \multicolumn{10}{|c|}{ Alcohol use disorders (F10) ${ }^{2}$} \\
\hline Denmark & 32.67 & 101.1 & 102.8 & 98.3 & 100.0 & 103.6 & 98.1 & 102.4 & 99.2 \\
\hline Finland & 25.34 & 113.6 & 104.2 & 104.8 & 100.0 & 107.4 & 102.4 & 97.7 & 100.2 \\
\hline Sweden-southern & 14.05 & 105.3 & 95.4 & 99.2 & 100.0 & 99.9 & 103.1 & 104.5 & 103.3 \\
\hline Sweden-northern & 14.12 & 112.8 & 118.3 & 113.2 & 100.0 & 102.4 & 102.2 & 106.9 & 113.5 \\
\hline \multicolumn{10}{|c|}{ Alcoholic liver disease (K70) } \\
\hline Denmark & 6.62 & 95.0 & 99.7 & 99.7 & 100.0 & 98.3 & 99.5 & 105.4 & 109.5 \\
\hline Finland & 4.73 & 90.3 & 91.9 & 98.2 & 100.0 & 114.3 & 133.3 & 124.5 & 124.3 \\
\hline Sweden-southern & 1.17 & 94.9 & 98.3 & 104.3 & 100.0 & 115.4 & 114.5 & 118.8 & 105.1 \\
\hline \multirow{3}{*}{ Sweden-northern } & 0.84 & 96.4 & 88.1 & 102.4 & 100.0 & 123.8 & 114.3 & 117.9 & 114.3 \\
\hline & $\begin{array}{c}\text { Standardized } \\
\text { rate per } 10,000\end{array}$ & \multicolumn{4}{|c|}{ Short-term effect 2003-2004 } & & & & \\
\hline & 2003 & t-test & p-value & Di & on of effect & & & & \\
\hline \multicolumn{10}{|c|}{ Alcohol-specific mortality ${ }^{1}$} \\
\hline Denmark & 44.95 & -1.605 & $0.169^{\mathrm{ns}}$ & & & & & & \\
\hline Finland & 46.09 & -11.351 & $<0.000^{* * *}$ & & $\pi$ & & & & \\
\hline Sweden-southern & 16.06 & -0.597 & $0.576^{\mathrm{ns}}$ & & & & & & \\
\hline Sweden-northern & 15.83 & -1.557 & $0.180^{\mathrm{ns}}$ & & & & & & \\
\hline \multicolumn{10}{|c|}{ Alcohol use disorders (F10) ${ }^{2}$} \\
\hline Denmark & 32.67 & -2.805 & $0.038^{\mathrm{ns}}$ & & $\pi$ & & & & \\
\hline Finland & 25.34 & -6.240 & $0.002^{* *}$ & & $\pi$ & & & & \\
\hline Sweden-southern & 14.05 & -0.127 & $0.904^{\mathrm{ns}}$ & & & & & & \\
\hline Sweden-northern & 14.12 & -0.862 & $0.428^{\mathrm{ns}}$ & & & & & & \\
\hline \multicolumn{10}{|c|}{ Alcoholic liver disease (K70) } \\
\hline Denmark & 6.62 & 4.265 & $0.008^{* *}$ & & $\mathbf{y}$ & & & & \\
\hline Finland & 4.73 & -3.934 & $0.011^{*}$ & & $\pi$ & & & & \\
\hline Sweden-southern & 1.17 & -5.440 & $0.003^{* *}$ & & $\pi$ & & & & \\
\hline Sweden-northern & 0.84 & -6.883 & $<0.001^{* * *}$ & & $\pi$ & & & & \\
\hline
\end{tabular}

Note. Arrows show significant short-term effects for 2003 to 2004 relative to general trend (one-sample $t$-test, $p<.05$ ): $\boldsymbol{\lambda}=$ stronger increase or weaker decrease; $\boldsymbol{y}=$ stronger decrease or weaker increase. Significance levels: $n s$ non-significant, ${ }^{*} p<0.05, * * p<0.01, * * * p<0.001$. Based on multi-cause coding of hospital discharges (primary causes). Note that the Swedish database does not distinguish F10.0-10.1 from F10.2, so only the combined category is available for $\mathrm{N}$ and S Sweden. All rates have been standardised (direct standardization): Average distribution of age groups in DK, FI, southern SE and northern SE over the years 2000-2007 has been used as standard population. ${ }^{1}$ ICD-10 Codes: DK = F10.0/1/2, E24.4, P04.3, G31.2, G62.1, I42.6, K29.2, K70, K86.0, Q86, R78.0, T51, Z50.2, Z71.4, Z72.1; FI = F10, G312, G621, G721, I426, K292, K70, K860, T51, E52, E24.4, P04.3, O35.4,Q86.0, Z50.2, Z71.4, Z72.1, R78.0 ; SE = F10, G312, G621, G721, I426, K292, K70, K860, T51, E52, E24.4, P04.3, O35.4, Q86.0, Z50.2, Z71.4, Z72.1, R78.0. ${ }^{2}$ ICD-10 codes: DK = F10.0-F10.2; FI = F10.0-F10.2; SE = all F10.

found in northern Sweden in the study can be viewed as the culmination of a longer-term trend in northern Sweden. In Finland, the changes strengthened the pre-existing increasing trend in consumption. In Denmark, consumption had been steady at the relatively high level of about 12 litres of ethanol per adult annually for three decades, and it has been suggested that the consumption level had "reached a saturation point" (Grittner et al.,
2009). Southern Sweden had also reached a high-point in consumption, although more recently than Denmark.

Limits on upward elasticity? Clearly the level of drinking in Denmark is not the maximum level a human population can sustain; any "saturation point" is going to be contingent on culture, social structure and epoch. To hypothesise saturation as an explanation for the findings in Denmark 
and southern Sweden is to propose that in that time and place the patterns of living and social norms function to limit any further net increase in drinking, so that the upward elasticity of demand becomes very small.

Increasing affluence, particularly in societies like Nordic countries with little extreme poverty, will in any case tend to decrease the elasticity of demand (Österberg, 1995). In recent decades, the affordability of alcohol has increased dramatically. In Finland, purchasing a bottle of the most popular spirits (Koskenkorva) required nearly three hours of industrial work in 1971, whereas in 2008, approximately 30 minutes of work was enough (Karlsson \& Österberg, 2009b). The real price index for spirits fell by 35\% in Denmark 2000-2007, 13\% beyond the 22\% decline in 2003-2004 (Skatteministeriet, 2010). Such trends of increased affordability can be observed in almost all EU countries (Rabinovitch et al., 2009). Hence, it may increasingly be the case that consumption already meets the demand and therefore price reductions no longer increase consumption. However, even when this is the case, an increase in price may decrease consumption. The literature has not yet followed up the suggestion that alcohol elasticities may be asymmetric (Bruun et al., 1975).

The novelty of cross-border shopping wears off? With regard to the small effects on travellers' imports in both Denmark and southern Sweden, such purchasing may be more attractive at first than later: the "charm of novelty" (Gustafsson, 2010a) may wear off. Both in Denmark and in Sweden, there had been previous increases in travellers' allowances-in Sweden on five occasions between 1995 and 2003 (Ramstedt \& Gustafsson, 2009) and in Denmark on five occasions between 1973 and 1993 (Bygvrå, 2009). While the relatively small increment of the first such change in Sweden had produced a marked effect (Norström, 2000), by the last increment in 2004 the novelty may have worn off.

Further evidence of the role of "charm of novelty" is the relatively short duration of the effects on travellers' imports found both in Sweden (Herttua et al., 2008) and in Denmark (Grittner \& Bloomfield, 2009). Economics distinguishes short-term from long-term elasticities, testing, for instance, whether and intervention has lasting effects or just triggers a "pulse" which subsides quickly. The elasticity triggered by changes in border shopping availability in these countries, the elasticity seems to be relatively short-term.

Distinct policy interventions in Denmark and Finland. It should be noted that the structure of change in taxes, and the overall effect on alcohol prices, differed between Denmark and Finland. The Danish tax change was only for spirits; although there is generally some crosselasticity between alcoholic beverages (Babor et al., 2010; Doran \& DiGiusto, 2011), only some consumers will change beverages in response to a change in the price differential. The incidence of switching to spirits from other alcoholic beverages in Denmark in 2004 was modest (Grittner et al., 2009). The Finnish tax change affected all alcoholic beverages to a greater or lesser extent, including reducing the price of the cheapest beverage per unit of ethanol, an aspect of pricing increasingly seen as an important influence on rates of problematic drinking (Stockwell, Auld, Zhao, \& Martin, 2012). A greater effect on consumption of the Finnish tax change than of the Danish, as in fact occurred, might therefore have been expected.

\section{Methodological considerations}

In the present study, the individual-level drinking survey results in Sweden and Denmark more or less match the register-data results based largely on sales data, but this was not true for Finland. Even if the total change in per capita consumption between 2003 and 2004 was nearly $10 \%$, it still corresponds to an average increase of only about 1.9 g. ethanol/day per inhabitant-about one drink per week. Given that survey responses only account for about half of alcohol sales (Rehm, Klotsche, \& Patra, 2007), the expected effect in the survey would have been smaller. To detect such or smaller effects, larger sample sizes would be needed to overcome the challenges of random error. Sampling biases are also a problem, due to sampling design (exclusions of the marginalised from the sampling frame) and relatively high non-response rates (Gmel \& Rehm, 2004). For the longitudinal studies, dropouts introduce a further bias. Self-reported consumption data in surveys thus has its limits as a tool for measuring small changes. In case of inconsistency, we consider the Nordic register data to be generally a more reliable source (Leifman, Österberg, \& Ramstedt, 2002).

It should also be noted that our self-report data are, of course, individual-level data. In the meta-analysis by Wagenaar et al. (2009), price elasticities are much smaller on average in the individual-level than in the aggregate-level studies. The difference is described there as the consequence of a "statistical artefact" reflecting higher variability at the individual level, but it is notable that, in their results for alcohol consumption as a whole, half of the 30 individual-level studies did not show a significant negative elasticity for price; four showed a zero elasticity; and two actually showed a significant positive elasticity. Our results are thus not outliers with respect to results from other individual-level studies.

\section{Future research directions}

In general, the study's results show that in Finland there is still a correspondence between alcohol prices with consumption and related harm. That chronic liver problems increased without delay is a sign that chronic heavy drinkers with pre-existing liver problems have been strongly affected by the tax cuts. That it was the non-employed who suffered in the first wave may be indicative of the same phenomenon.

However, for Denmark and southern Sweden, there were only small or no effects of the changes in tax and travellers' allowances. The cultural determinants of why middle aged and older Finns are thirstier than Danes and 
Swedes are hard to establish, let alone to predict. Defining and empirically testing the boundary conditions of price elasticity and saturation should thus be a priority of future research (Room et al., 2009). Clearly, the study adds to the evidence that in high-income countries the increase in alcohol affordability during the last decades has already increased total alcohol consumption to the level where further increases in affordability may no longer substantially increase consumption.

\section{References}

Anderson, P., Chisholm, D., \& Fuhr, D. (2009). Effectiveness and cost-effectiveness of policies and programmes to reduce the harm caused by alcohol. Lancet, 373, 2234-2246.

Babor, T., Caetano, R., Casswell, S., Edwards, G., Giesbrecht, N., Graham, K., ... Rossow, I. (2010). Alcohol: No ordinary commodity: Research and public policy $\left(2^{\text {nd }}\right.$ ed.). Oxford, England: Oxford University Press.

Bloomfield, K., Rossow, I., \& Norström, T. (2009). Changes in alcohol-related harm after alcohol policy changes in Denmark. European Addiction Research, 15, 224-231.

Bloomfield, K., Wicki, M., Gustafsson, N.-K., Mäkelä, P., \& Room R. (2010). Changes in alcohol-related problems after alcohol policy changes in Denmark, Finland, and Sweden. Journal of Studies on Alcohol and Drugs, 71, 32-40.

Bruun, K., Edwards, G., Lumio, M., Mäkelä, K., Pan, L., Popham, R. E., ... Österberg, E. (1975). Alcohol control policies in public health perspective. Helsinki, Finland: Finnish Foundation for Alcohol Studies.

Buch, C. M., Kleinert, J., \& Toubal, F. (2004). The distance puzzle: On the interpretation of the distance coefficient in gravity equations. Economics Letters, 83, 293-298.

Bygvrå, S. (2009). Distance and cross-border shopping for alcohol: Evidence from Danes' cross-border shopping 1986-2003. Nordic Studies on Alcohol \& Drugs, 26, 141-163.

Doran, C., \& DiGiusto, E. (2011). Using taxes to curb drinking: A report card on the Australian government's alcopops tax. Drug and Alcohol Review, 30, 677-680.

Fogarty, J. (2006). The nature of the demand for alcohol: Understanding elasticity. British Food Journal, 108, 316-332.

Gallet , C. A. (2007). The demand for alcohol: A metaanalysis of elasticities. Australian Journal of Agricultural and Resource Economics, 51, 121-135.

Gmel, G., \& Rehm, J. (2004). Measuring alcohol consumption. Contemporary Drug Problems, 31, 467-540.

Gmel G., Wicki, M., Rehm, J., \& Heeb, J. L. (2008). Estimating regression to the mean and true effects of an intervention in a four-wave panel study. Addiction, 103, 32-41.
Grittner, U., \& Bloomfield, K. (2009). Changes in private alcohol importation after alcohol tax reductions and import allowance increases in Denmark. Nordic Studies on Alcohol and Drugs, 26, 177-191.

Grittner, U., Gmel, G., Ripatti, S., Bloomfield, K., \& Wicki, M. (2011). Missing value imputation in longitudinal measures of alcohol consumption. International Journal of Methods in Psychiatric Research, 20, 50-61.

Grittner, U., Gustafsson, N.-K., \& Bloomfield, K. (2009). Changes in alcohol consumption in Denmark after the tax reduction on spirits. European Addiction Research, 15, 216-223.

Gustafsson, N.-K. (2010a). Bridging the world: Alcohol policy in transition and diverging alcohol patterns in Sweden. PhD Dissertation. Stockholm Studies in Sociology, New Series 42. Stockholm, Sweden: Stockholm University.

Gustafsson, N.-K. (2010b). Alcohol consumption in southern Sweden after major decreases in Danish spirits taxes and increases in Swedish travelers' quotas. European Addiction Research, 16, 152-161.

Helakorpi, S., Mäkelä, P., \& Uutela, A. (2010). Alcohol consumption before and after a significant reduction of alcohol prices in 2004 in Finland: Were the effects different across population subgroups? Alcohol \& Alcoholism, 45, 286-292.

Helakorpi, S., Patja, K., Prättälä, R., \& Uutela, A. (2005). Health behaviour and health among the Finnish adult population, Spring 2005. Helsinki, Finland: Publications of the National Public Health Institute. http://www.ktl.fi/attachments/suomi/ julkaisut/julkaisusarja_b/2005/2005b18.pdf Accessed: 2011-09-18. (Archived by WebCite ${ }^{\circledR}$ at http://www.webcitation. org/61nfsgj9B)

Herttua, K. (2010). The effects of the 2004 reduction in the price of alcohol on alcohol-related harm in Finland: A natural experiment based on register data. PhD dissertation. Finnish Yearbook of Population Research 45, Supplement. Helsinki, Finland: Population Research Institute.

Herttua, K., Mäkelä, P., \& Martikainen, P. (2008). Changes in alcohol-related mortality and its socioeconomic differences after a large reduction in alcohol prices: A natural experiment based on register data. American Journal of Epidemiology, $168,1110-1118$.

Justitsministeren. (2005). Pas på kørekortet! [Be careful driving!] Press release. Copenhagen, Denmark: Justice Ministry. http://www.justitsministeriet.dk/ pressemeddelelse+M539ea647321.html?\&tx_ttnews \%5bmonth\%5d=08\&tx_ttnews\%5byear\%5d=2005 Accessed: 2011-09-18. (Archived by WebCite ${ }^{\circledR}$ at http://www.webcitation.org/61nf3 okxr)

Kahn, H. A., \& Sempos, C. T. (1989). Statistical methods in epidemiology. Oxford, England: Oxford University Press.

Karlsson, T., \& Österberg, E. (2009a). The Nordic borders are not all alike. Nordic Studies on Alcohol \& Drugs, 26, 117-139. 
Karlsson, T., \& Österberg, E. (2009b). Alcohol affordability and cross-border trade in alcohol. Östersund, Sweden: Swedish National Institute of Public Health Retrieved from http://www.fhi.se/ PageFiles/7308/A2009-06-Alcohol-affordabilityand-cross-border-trade.pdf (accessed 1 January, 2011)

Leifman, H., Österberg, E., \& Ramstedt, M. (2002). Alcohol in postwar Europe, ECAS II: A discussion of indicators on alcohol consumption and alcoholrelated harm. Stockholm, Sweden: National Institute of Public Health - Sweden. http://www.fhi. se/en/ Publications/All-publications-in-english/ Alcohol-in-postwar-Europe-ECAS-II/ Accessed: 2011-09-18. (Archived by WebCite ${ }^{\circledR}$ at http://www.webcitation. org/61ngldCU1).

Lhachimi, S. (2006). The combined effect of petrol prices and distance on the demand in for alcoholic beverage in Sweden after the lift of the import restrictions in 2004. Working paper. Colchester, England: University of Essex.

Mäkelä, P., Bloomfield, K., Gustafsson, N.-K., Huhtanen, P., \& Room, R. (2008). Changes in volume of drinking after changes in alcohol taxes and travellers' allowances: Results from a panel study. Addiction, 103, 81-91.

Mäkelä, P., Bloomfield, K., Gustafsson, N.-K., \& Room, R. (2007). Effects of major changes in alcohol availability: Study design, data collection procedures and measurement. Research Report No. 46. Stockholm, Sweden: SoRAD, Stockholm University. http://www2.sorad.su.se/publications. php?Id=539 Accessed: 2011-09-18. (Archived by WebCite $^{\circledR}$ at http://www.webcitation.org/61ndyy LEA)

Mäkelä, P., \& Huhtanen, P. (2010). The effect of survey sampling frame on coverage: The level of and changes in alcohol-related mortality in Finland as a test case. Addiction, 105, 1935-1941.

Mäkelä, P., \& Österberg, E. (2009). Weakening of one more alcohol control pillar: A review of the effects of the alcohol tax cuts in Finland in 2004. Addiction, 104, 554-563.

Mustonen, H., Mäkelä, P., \& Huhtanen, P. (2007). People are buying and importing more alcohol than ever before: Where is it all going? Drugs: Education, Prevention and Policy, 14, 513-527.

Mustonen, H., Mäkelä, P., Huhtanen, P., Metso, L., \& Raitasalo, K. M. (2005). Det köps och införs mer alkohol än någonsin: Vart försvinner den? [Alcohol is purchased and imported more than ever: Where does it disappear?] Nordisk Alkohol \& Narkotikatidskrift, 22, 209-228.

Norström, T. (2000). The geography of cross-border trading of alcohol. In: H. Holder (Ed.), Sweden and the European Union: Changes in national alcohol policy and their consequences (pp. 121-135). Stockholm, Sweden: Almqvist \& Wiksell.

Österberg, E. (1995). Do alcohol prices affect consumption and related problems? In H. D. Holder \& G. Edwards (Eds.), Alcohol and public policy:
Evidence and issues (pp. 145-163). New York, NY, United States: Oxford University Press.

Rabinovitch, L., Brutscher, P.-B., de Vried, H., Tiessen, J., Clift, J., \& Reding, A. (2009). The affordability of alcoholic beverages in the European Union: Understanding the link between alcohol affordability, consumption and harms. Cambridge, United Kingdom: RAND Europe. http://www. rand.org/pubs/technical_reports/TR689 Accessed: 2011-09-18. (Archived by WebCite ${ }^{\circledR}$ at http://www. webcitation.org/61ngNY4dE)

Ramstedt, M., \& Gustafsson, N.-K. (2009). Increasing travellers' allowances in Sweden: How did it affect travellers' imports and Systembolaget's sales? Nordic Studies on Alcohol \& Drugs, 26, 165-176.

Rehm, J., Klotsche, J., \& Patra, J. (2007). Comparative quantification of alcohol exposure as risk factor for global burden of disease. International Journal of Methods in Psychiatric Research, 16, 66-76.

Ripatti, S., \& Mäkelä, P. (2007, June). Selection and bias in panel surveys on alcohol consumption. Paper presented at the 33rd Annual Alcohol Symposium of the Kettil Bruun Society, Budapest, Hungary.

Ripatti, S., \& Mäkelä, P. (2008). Conditional models accounting for regression to the mean in observational multi-wave panel studies on alcohol consumption. Addiction, 103, 24-31.

Room, R., Österberg, E., Ramstedt, M., \& Rehm, J. (2009). Explaining change and stasis in alcohol consumption. Addiction Research and Theory, 17, 562-576.

Sirén R., \& Lehti, M. (2006). Did increased alcohol consumption lead to more violence? The impact of 2004 tax cuts and relaxation of import restrictions of alcohol on crimes of violence and disorder. English Summary of NRILP Publication 222, Helsinki, Finland: National Research Institute of Legal Policy, http://www.optula.om.fi/en/ Oikeapalsta/Haku/1215523701979 Accessed: 201109-18. (Archived by WebCite ${ }^{\circledR}$ at http://www.web citation.org/61nfW03z5)

Skatteministeriet. (2010). Status over Grænsehandel: Maj 2010 [Status of border trade, May 2010]. Copenhagen, Denmark: Author. http://www.skm. dk/publikationer/udgivelser/8145/ Accessed: 201109-18. (Archived by WebCite ${ }^{\circledR}$ at http://www.web citation.org/61ndPb6bK)

Smith, A. (1977). An inquiry into the nature and causes of the wealth of nations (first published 1776). Chicago, IL, United States: University of Chicago Press.

Stockwell, T., Auld, M. C., Zhao, J., \& Martin, G. (2012). Does minimum pricing reduce alcohol consumption? The experience of a Canadian province. Addiction, 107, 912-920.

Wagenaar, A. C., Salois, M. J., \& Komro, K. A. (2009). Effects of beverage alcohol price and tax levels on drinking: A meta-analysis of 1003 estimates from 112 studies. Addiction, 104, 179-190. 